\title{
Assessment of animal welfare in a veterinary context - a call for ethologists
}

Christiansen, Stine Billeschou; Forkman, Björn

Published in:

Applied Animal Behaviour Science

DOI:

10.1016/j.applanim.2007.01.004

Publication date:

2007

Document version

Publisher's PDF, also known as Version of record

Citation for published version (APA):

Christiansen, S. B., \& Forkman, B. (2007). Assessment of animal welfare in a veterinary context - a call for ethologists. Applied Animal Behaviour Science, 106(4), 203-220. https://doi.org/10.1016/j.applanim.2007.01.004 


\title{
Assessment of animal welfare in a veterinary context - a call for ethologists ${ }^{1}$
}

\author{
S. B. Christiansen ${ }^{1} * \&$ B. Forkman ${ }^{2}$
}

${ }^{1}$ The Royal Veterinary and Agricultural University, Centre for Bioethics and Risk Assessment, Denmark

${ }^{2}$ The Royal Veterinary and Agricultural University, Division of Ethology, Denmark

*Correspondence: telephone no.: + 453528 3075, fax no.: + 453528 3022, email: sbc@kvl.dk

\begin{abstract}
With the increasingly advanced treatments offered in veterinary medicine, the need to evaluate not only the treatment itself but also the implications of the treatment for the welfare of the animal has become more apparent. Follow-up studies are important sources of information for veterinarians concerning the potential outcome of a treatment and some of these studies include a statement concerning the welfare of the animal involved. In veterinary medicine the concept of animal welfare is often equated to health status, but it is important to distinguish between the success of the treatment in restricted terms, i.e. the health aspects; and the success in more global terms, i.e. how the general welfare of the animal is during and after the treatment.
\end{abstract}

A qualitative analysis was done on 32 follow-up studies of veterinary treatment given to dogs and cats, making reference to the terms "animal welfare", "quality of life" or "well-being". The studies typically speak about "quality of life", and rarely define the terms used. The parameters used to assess animal

\footnotetext{
${ }^{1}$ The reference of the printed version is:

Stine Billeschou Christiansena \& Björn Forkman (2007): Assessment of animal welfare in a veterinary context —A call for ethologists. Applied Animal Behaviour Science 106: 203-220.

The definitive version is available at http://www.appliedanimalbehaviour.com/article/S0168-1591\%2807\%2900031-7/abstract
} 
welfare are primarily related to clinical aspects, while behavioural parameters for a broader welfare assessment - if used at all - are often crude. The assessments are made by animal owners, and sometimes also by veterinarians.

These results have severe implications for the validity and sensitivity of such studies. Seen from an ethological point of view, most studies are lacking sufficient broadness and detail in the parameters used to provide a basis for animal welfare assessments beyond a clinical evaluation. Veterinarians and animal owners do not necessarily have the required ethological knowledge to assess animal welfare in a broader sense. And both may be personally involved and thus introduce a bias in the assessment.

The development and validation of parameters and instruments for animal welfare assessment in a veterinary context is necessary and could benefit from the expertise, experience and more impartial position of ethologists. This work would be useful in both prospective and retrospective follow-up studies, and could support the assessments done on a daily basis by the practicing vet. As an inspiration for ethologists to get involved, suggestions are made of potential contributions from ethology to animal welfare assessment in a veterinary context.

Keywords: Animal welfare assessment, Quality of life, Follow-up studies, Veterinary medicine, Dog, Cat

\section{Introduction}

Veterinary medicine, in particular small animal practice, offers increasingly advanced medical treatments of the animal patients. Typically, more systematic evaluations of the success of a treatment are done by follow-up studies, where the owners of the animal patients and perhaps also the veterinarian provide information about the outcome of the treatment and whether side effects and complications were observed. But even though a treatment is successful, the general welfare of the animal involved may still be severely affected by the treatment, possible side effects or even the 
medical condition itself. The use of more sophisticated treatments underlines the need to evaluate not only the success of the treatment itself but also the implications of the illness and treatment for the general welfare of the animal. Therefore the need for animal welfare assessments in a veterinary context and development of proper instruments for this assessment has become more apparent (Wojciechowska and Hewson, 2005).

Follow-up studies are important sources of information for veterinarians concerning the potential outcome of a treatment and besides serving as a basis for advances in veterinary medicine, they may play an important role when giving advice to and preparing other owners facing similar treatment options for their animal. Some of these studies consider the animal's "welfare" or "quality of life", but in veterinary medicine the concept of "quality of life" is often equated to health status (McMillan, 2000), and "quality of life" assessments in a veterinary context thus typically focus on assessment of health (McMillan, 2000; Wojciechowska et al., 2005b). In their study, Skurla et al. (2000) asked separate questions about welfare and health, and although factors such as health and pain can have a profound impact on welfare (McMillan, 2003; Wiseman-Orr et al., 2004), the concept of welfare is generally thought of as more than health when used in applied ethology (Dawkins, 1980) and may involve more aspects of an animal's life in relation to animal care (McMillan, 2003).

If the evaluation of animal welfare in a follow-up study is focused too narrowly on clinical aspects such as the treatment and possible complications, it may fail to identify other aspects of the animal's life, which may be affected by the disease and/or treatment. One could then end up with a conclusion where the treatment was considered successful and the welfare acceptable, but - although the patient didn't die - one might overlook the fact that the animal still suffered or experienced difficulties. It is therefore important to distinguish between the success of the treatment in restricted terms, i.e. the health aspects; and the success in more global terms, i.e. how the general welfare of the animal is during and after the treatment. For example, a follow-up study on leg amputations in dogs could from a health point of view only consider healing of the amputation site, time to adjust and functionality, and ignore potential changes in social behaviour e.g. in relation to other dogs. A broad approach to assessment of animal 
welfare is thus essential in a veterinary context in order to obtain information about all affected aspects of the animal's life.

From an ethological point of view the fact that some follow-up studies include evaluations of animal welfare is of interest - in particular as the approach to this evaluation seems to pay little attention to aspects beyond a health assessment. Thus animal welfare assessments in a veterinary context may be perceived as having a potential for development - possibly in collaboration with the field of applied ethology. Seen from a more general point of view the approaches to welfare assessment in a veterinary context may be very important as these have implications for the usefulness of such studies as a basis for advice.

The aim of this paper is first to analyse the approaches of follow-up studies to assessment of animal welfare in a veterinary context, when such studies go beyond the purely clinical aspects and lead to more general statements about of animal welfare. Secondly, the implication of these approaches for the use of such studies as a basis for veterinary advice will be discussed. Finally, examples are made to suggest development of animal welfare assessment in a veterinary context, drawing upon the field of ethology.

\section{Materials and methods}

The analysis concerned only papers that made an explicit contribution to the assessment of animal welfare beyond the clinical evaluation of the treatment in question (although success of a given treatment, potential side-effects and complications will obviously also affect animal welfare). Therefore, papers concerning follow-up studies have been included only when making a direct reference to the state of the animal by the words "quality of life", "welfare" or "well-being". This criterion was chosen, as the use of these terms implies that the conclusions of the papers can be perceived as reflecting a broader welfare assessment than just an evaluation of the treatment success.

A literature search revealed 32 papers on follow-up studies from small animal practice, concerning more than one animal and published in English (Table 1). There are no standardised frameworks for 
carrying out such studies and no standardised search terms. Consequently, although the attempt was to find all studies matching the criterion for inclusion, the search may not be exhaustive. If the criterion was met, the papers were included regardless of the medical condition and treatment being evaluated.

As the purpose of this paper was to look at the nature of approaches to welfare assessment, a qualitative analysis was chosen. In addition to this, when appropriate, the proportions of the findings within the material were noted. The papers were analysed for the following factors:

1. Choice of terminology concerning welfare-related concepts referred to in the paper. It was recorded whether or not the terms used were defined, and if so, whether reference was made to definitions of similar terms in philosophy, ethology or human medicine.

2. The specific parameters used to assess animal welfare. It was also noted whether global questions were asked as these may be used to support the evaluation of animal welfare.

3. The persons or other sources involved in the assessment of animal welfare.

For the purpose of this paper the term "welfare" will be used, as this is the most widely used in an ethological context for evaluations relating to the state of the animal. It will be considered equal to "quality of life", "health-related quality of life" and "well-being", and will in some cases be used also when making reference to authors who speak about these other terms.

\section{Results}

The findings from the 32 papers included in the analysis have been summarised in Table 1. The construction of the categories of the table is based on the qualitative analysis. These categories will be explained further below. The proportions of the findings are listed in the text below when appropriate. 
Table 1: Follow-up studies analysed and an overview of the findings

\begin{tabular}{|c|c|c|c|c|c|c|c|c|c|c|c|}
\hline \multirow[t]{3}{*}{ Paper } & \multicolumn{2}{|c|}{ Terminology $^{1}$} & \multicolumn{7}{|c|}{ Animal welfare parameters ${ }^{2}$} & \multirow{3}{*}{$\begin{array}{l}\text { Global } \\
\text { questions }\end{array}$} & \multirow{3}{*}{\begin{tabular}{|l|}
$\begin{array}{l}\text { Source of } \\
\text { information }^{3}\end{array}$ \\
Own, Vet, Med
\end{tabular}} \\
\hline & \multirow[t]{2}{*}{$\begin{array}{l}\text { QoL, WB, } \\
\text { WF }\end{array}$} & \multirow[t]{2}{*}{ Def } & \multicolumn{4}{|c|}{ Clinical aspects } & \multicolumn{3}{|c|}{$\begin{array}{l}\text { General animal } \\
\text { welfare assessment }\end{array}$} & & \\
\hline & & & Mort & Trea & Impl & Pain & Func & Soc & Men & & \\
\hline Bass et al., 2005 & QoL & - & $\mathrm{X}$ & $\mathrm{X}$ & $\mathrm{X}$ & - & - & - & - & $\mathrm{X}$ & Own, Vet \\
\hline Bateman et al., 1994 & QoL & + & $\mathrm{X}$ & $\mathrm{X}$ & $\mathrm{X}$ & $\mathrm{X}$ & $\mathrm{X}$ & $\mathrm{X}$ & - & $\mathrm{X}$ & Own, Vet \\
\hline Bauer et al., 1992 & QoL, WB & - & $\mathrm{X}$ & - & $\mathrm{X}$ & - & $\mathrm{X}$ & - & $\mathrm{X}$ & $\mathrm{X}$ & Own \\
\hline Boothe et al., 1996 & QoL & - & $\mathrm{X}$ & $\mathrm{X}$ & $\mathrm{X}$ & - & - & - & - & $\mathrm{X}$ & Own, Vet \\
\hline Brissot et al., 2004 & QoL & + & $\mathrm{X}$ & $\mathrm{X}$ & $\mathrm{X}$ & $\mathrm{X}$ & $\mathrm{X}$ & $\mathrm{X}$ & $X$ & $\mathrm{X}$ & Own, Vet \\
\hline Brønden et al., 2003 & QoL & - & $\mathrm{X}$ & $\mathrm{X}$ & $\mathrm{X}$ & $\mathrm{X}$ & - & - & $\mathrm{X}$ & $\mathrm{X}$ & Own \\
\hline Craven et al., 2004 & QoL, WB & + & $\mathrm{X}$ & $\mathrm{X}$ & $\mathrm{X}$ & - & - & - & - & $\mathrm{X}$ & Own, Vet \\
\hline Fox et al., 1997 & QoL & - & $\mathrm{X}$ & $\mathrm{X}$ & $\mathrm{X}$ & $\mathrm{X}$ & $\mathrm{X}$ & - & - & $\mathrm{X}$ & Own \\
\hline
\end{tabular}




\begin{tabular}{|c|c|c|c|c|c|c|c|c|c|c|c|}
\hline Fox et al., 2000 & QoL & - & $\mathrm{X}$ & $\mathrm{X}$ & $\mathrm{X}$ & - & $\mathrm{X}$ & $\mathrm{X}$ & $\mathrm{X}$ & - & Own, Vet \\
\hline Holt and Durdey, 1999 & QoL & - & $\mathrm{X}$ & $\mathrm{X}$ & $\mathrm{X}$ & $\mathrm{X}$ & - & - & - & - & Own \\
\hline Jeffery and Brearley, 1993 & QoL & - & $\mathrm{X}$ & $\mathrm{X}$ & $\mathrm{X}$ & - & $\mathrm{X}$ & $\mathrm{X}$ & $\mathrm{X}$ & - & Own, Vet \\
\hline Johnson et al., 1987 & QoL & - & $\mathrm{X}$ & $\mathrm{X}$ & $\mathrm{X}$ & - & - & - & - & $\mathrm{X}$ & Own, Vet \\
\hline Kirpensteijn et al., 1999 & QoL & - & $\mathrm{X}$ & - & $\mathrm{X}$ & - & $\mathrm{X}$ & $\mathrm{X}$ & $\mathrm{X}$ & $\mathrm{X}$ & Own \\
\hline Lord and Podell, 1999 & QoL & + & $\mathrm{X}$ & $\mathrm{X}$ & $\mathrm{X}$ & - & $\mathrm{X}$ & - & $\mathrm{X}$ & $\mathrm{X}$ & Own \\
\hline Macintire et al., 2001 & QoL & - & $X$ & $\mathrm{X}$ & $\mathrm{X}$ & $\mathrm{X}$ & - & - & $\mathrm{X}$ & - & Own, Vet, Med \\
\hline Malik et al., 2001 & QoL & - & $\mathrm{X}$ & $\mathrm{X}$ & $\mathrm{X}$ & - & - & - & - & $X$ & Own, Vet \\
\hline Mallery et al., 1999 & QoL & - & $\mathrm{X}$ & $\mathrm{X}$ & $\mathrm{X}$ & - & $\mathrm{X}$ & - & - & $\mathrm{X}$ & Own, Vet, Med \\
\hline McCaw et al., 1997 & QoL & - & $\mathrm{X}$ & $\mathrm{X}$ & $\mathrm{X}$ & - & - & - & - & - & Vet \\
\hline Mellanby et al., 2003 & QoL & - & $\mathrm{X}$ & $\mathrm{X}$ & $\mathrm{X}$ & - & - & - & $\mathrm{X}$ & $\mathrm{X}$ & Own \\
\hline Meyer et al., 1999 & WB & - & $\mathrm{X}$ & $X$ & $\mathrm{X}$ & - & $\mathrm{X}$ & $\mathrm{X}$ & $\mathrm{X}$ & $\mathrm{X}$ & Own, Vet \\
\hline Oglivie et al., 1993 & QoL & - & $\mathrm{X}$ & $\mathrm{X}$ & $\mathrm{X}$ & - & $\mathrm{X}$ & - & $\mathrm{X}$ & - & Own, Vet \\
\hline Oyama et al., 2001 & QoL & - & $\mathrm{X}$ & $\mathrm{X}$ & $\mathrm{X}$ & - & - & - & - & $\mathrm{X}$ & Own, Med \\
\hline
\end{tabular}




\begin{tabular}{|c|c|c|c|c|c|c|c|c|c|c|c|}
\hline Ranen et al., 2004 & QoL & - & $\mathrm{X}$ & $\mathrm{X}$ & $\mathrm{X}$ & - & $\mathrm{X}$ & - & - & $\mathrm{X}$ & Own, Vet \\
\hline Rochlitz, 2004 & WF & - & $\mathrm{X}$ & $\mathrm{X}$ & $\mathrm{X}$ & - & $\mathrm{X}$ & $\mathrm{X}$ & $\mathrm{X}$ & - & Own, Med \\
\hline Skurla et al., 2000 & QoL, WB & - & $\mathrm{X}$ & - & - & $\mathrm{X}$ & $\mathrm{X}$ & - & - & $\mathrm{X}$ & Own \\
\hline Slater et al., 1996 & QoL & - & $\mathrm{X}$ & $\mathrm{X}$ & $\mathrm{X}$ & - & $\mathrm{X}$ & $\mathrm{X}$ & - & $\mathrm{X}$ & Own \\
\hline Smith et al., 1995 & QoL & - & $\mathrm{X}$ & $\mathrm{X}$ & $\mathrm{X}$ & - & - & - & - & $\mathrm{X}$ & Own \\
\hline Snelling and Edwards, 2003 & QoL & - & $\mathrm{X}$ & $\mathrm{X}$ & $\mathrm{X}$ & - & $\mathrm{X}$ & - & - & $\mathrm{X}$ & Own, Vet \\
\hline Stone et al., 1988 & QoL & - & $X$ & $\mathrm{X}$ & $\mathrm{X}$ & - & - & - & - & $\mathrm{X}$ & Own \\
\hline Watson and Herrtage, 1998 & QoL & - & $\mathrm{X}$ & $\mathrm{X}$ & $\mathrm{X}$ & - & - & - & - & $\mathrm{X}$ & Own, Vet \\
\hline Withrow, 1980 & QoL & - & $\mathrm{X}$ & $\mathrm{X}$ & $\mathrm{X}$ & $\mathrm{X}$ & $\mathrm{X}$ & - & - & $\mathrm{X}$ & Own, Vet \\
\hline Yearley et al., 2004 & QoL & - & $\mathrm{X}$ & $\mathrm{X}$ & $\mathrm{X}$ & - & - & - & - & $\mathrm{X}$ & Own, Vet, Med \\
\hline
\end{tabular}

${ }^{1}$ Terminology: QoL: “quality of life”, WB: “well-being”, WF: “welfare.

${ }^{2}$ Animal welfare parameters: Parameters relating to clinical aspects: Mort: mortality, Trea: treatment success, Impl: implications of medical condition or treatment, Pain: pain. Parameters relating to general welfare assessment: Func: functionality, Soc: social behaviour, Men: mental state.

${ }^{3}$ Sources of information: Own: owner, Vet: veterinarian, Med: medical record. 


\subsection{Use of terminology and definitions}

The vast majority of papers used the term "quality of life" (30/94\%), only few talked about "wellbeing" $(4 / 13 \%)$ and "welfare" $(1 / 3 \%)$. Some papers used more than one term. Only in 4 papers $(13 \%)$ did the authors offer some specification about their understanding of the term "quality of life", by relating this concept to pain (Bateman et al., 1994), by definition as owners' perception of certain aspects (Craven et al., 2004), by providing criteria for response categories (Brissot et al., 2004) or by identifying questions in a questionnaire used for the welfare assessment (Lord and Podell, 1999). No reference was made in any of the papers to definitions of "welfare" or "quality of life" presented and discussed in other contexts.

\subsection{Assessing animal welfare}

Typically, the parameters used for assessment in follow-up studies are directly or indirectly related to the particular disease and treatment being evaluated. Thus, they generally reflect a veterinary assessment including both medical and behavioural observations. It could thus be argued that they were all health-related parameters. However, even though the changes observed may all be healthrelated, some of the parameters themselves still have the potential to provide information relating to a broader and more general welfare assessment.

The first grouping of parameters reflected whether or not these were considered by the authors of this paper to be primarily of relevance to the clinical assessment. Clinical assessment parameters were defined as parameters that would be of interest when evaluating an illness/treatment, and in nature would be specific to the illness/treatment in question. These were categorised as parameters relating to "Clinical aspects".

The other parameters, although also reflecting consequences of an illness/treatment, had the potential to contribute to a broader welfare assessment and were similar to the behavioural parameters typically used in an ethological context. These parameters thus relate to both clinical aspects and a general animal welfare assessment. Because the approach to a general welfare assessment is of particular interest in this paper and for the sake of simplicity, these parameters will be referred to as parameters relating to a "General welfare assessment". Both of these main categories were divided further in several subcategories. An overview of the main and subcategories and examples of the parameters included in these categories is presented in Table 2. 
Table 2: Generated main and subcategories of parameters and examples of parameters defining each category

\begin{tabular}{|c|c|c|c|c|c|c|}
\hline \multicolumn{4}{|c|}{ Clinical aspects } & \multicolumn{3}{|c|}{ General welfare assessment } \\
\hline Mortality & Treatment & Implications & Pain & Functionality & $\begin{array}{l}\text { Social } \\
\text { behaviour }\end{array}$ & Mental state \\
\hline $\begin{array}{l}\text { - Survival } \\
\text { times } \\
\text { - No. of dead } \\
\text { - Causes of } \\
\text { death } \\
\text { - Reasons for } \\
\text { euthanasia }\end{array}$ & $\begin{array}{l}\text { - Kinds of } \\
\text { treatment } \\
\text { - Response to } \\
\text { treatment } \\
\text { - Clinical } \\
\text { progress } \\
\text { - Recurrence } \\
\text { - Recovery } \\
\text { - Cure }\end{array}$ & $\begin{array}{l}\text { - Complications } \\
\text { - Side-effects } \\
\text { - Bodyweight } \\
\text { - Appetite }\end{array}$ & $\begin{array}{l}\text { - Expression } \\
\text { - Scoring } \\
\text { - Medication } \\
\text { - Manageme } \\
\text { nt }\end{array}$ & $\begin{array}{l}\text { - Activity } \\
\text { level } \\
\text { - Adaptation } \\
\text { - Benefit of } \\
\text { aid } \\
\text { - Ability to } \\
\text { e.g. } \\
\text { walk/run/eat } \\
\text { / } \\
\text { exercise/jum } \\
\text { p/ groom }\end{array}$ & $\begin{array}{l}\text { - Aggressi } \\
\text { on } \\
\text { - Vocalisat } \\
\text { ion } \\
\text { - Play } \\
\text { - Dominan } \\
\text { ce } \\
\text { - Lack of } \\
\text { interest } \\
\text { - Affection } \\
\text { ate }\end{array}$ & $\begin{array}{l}\text { - Attitude } \\
\text { - Awareness } \\
\text { of handicap } \\
\text { - Depression } \\
\text { - Anxiety }\end{array}$ \\
\hline
\end{tabular}

The main and subcategories were generated on the basis of the parameters used in the studies. There are other possible ways of categorising the parameters, and the choice made here is to some extent based on a subjective judgement. This approach, however, has the advantage of allowing the evaluations as they are presented in the studies determine the nature of the categories. The parameters concerning pain could for example have been considered part of "Implications" but were put in a separate "Pain" subcategory as, when included in the studies, this aspect was often given a lot of attention. Bateman et al. (1994) use a pain score system as part of the welfare assessment, and the general importance of pain in veterinary medicine is emphasized by the development of pain assessment tools (e.g. Holton et al., 2001 (acute pain); Hielm-Björkman et al., 2003 (chronic pain) and Hudson et al., 2004 (pain and lameness)). Due to the diversity of medical conditions, treatments and assessments dealt with in the papers, no clear-cut distinction could be made in and across all cases between parameters assigned to the "Treatment" and "Implications" categories. However, as the parameters concerning a general welfare assessment are of primary 
interest for the purpose of this paper, such clarity in distinction of the clinical parameters was considered less important. Finally, it could be argued, that some of the parameters in the general welfare assessment category, depending on the medical condition could just as well be considered part of the clinical parameters, e.g. depression (for animals suffering from toxicity) and activity level (for animals suffering from lameness). All parameters in the main category relating to general welfare assessment do, however, have the potential to be part of a broader welfare assessment regardless of their clinical context in a particular study, and thus were consistently put in this main category when recognised.

When it was unclear whether a question could be interpreted as relating to one or another subcategory, all possible response categories have been marked in Table 1, e.g. when Meyer et al. (1999) ask owners about observations of "abnormal behaviour", the responses could reflect observations concerning "Functionality", "Social behaviour" and/or "Mental state". The same marking approach was used when authors used multiple parameters to assess one aspect, e.g. a pain score system based on "appetite", "activity level" and "lameness" (Bateman et al., 1994) elicited marks in the subcategories "Implications" (appetite), "Pain" (scoring), "Functionality" (activity level and lameness) and "Social behaviour" (activity level). The subcategories have been marked regardless of whether the parameters were brought up by the authors themselves or by the owner responses as reported by the authors.

The proportion of studies including one or more parameters from each subcategory is illustrated in Fig. 1. Parameters from the main category "Clinical aspects" have been included most often. In 12 studies $(38 \%)$ these parameters are the only specific parameters used. In some studies parameters concerning "Functionality" (6/19\%) are included as well. Only 6 studies (19\%) include parameters from all subcategories of the general welfare assessment ("Functionality", "Social behaviour" and "Mental state"), and in 18 studies (56\%) neither "Social behaviour" parameters nor "Mental state" parameters have been used. 
Fig. 1: Percentage of studies including one or more parameters from each subcategory

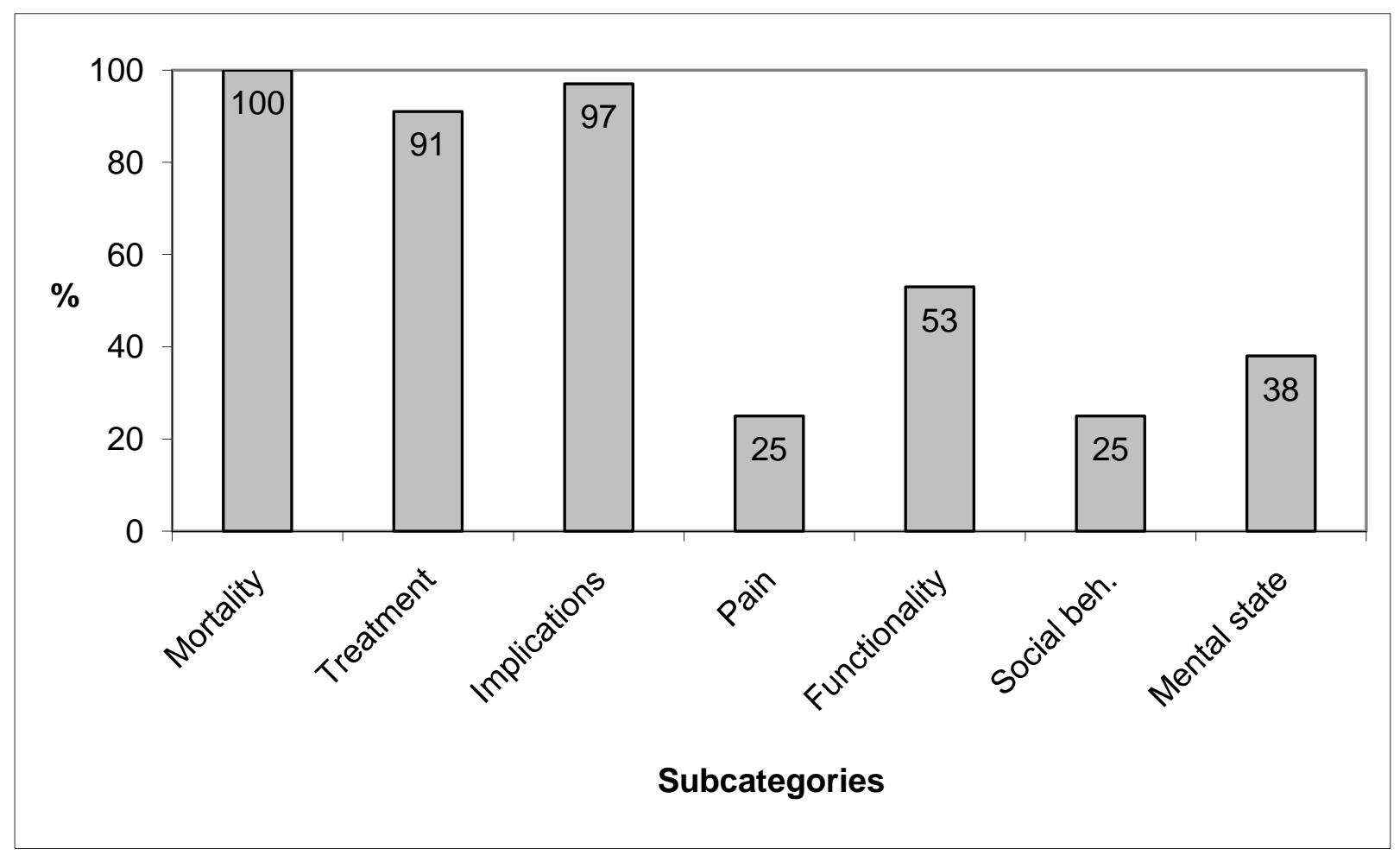

It is important to keep in mind that not all subcategories in the main category "Clinical parameters" may be relevant to all studies. In contrast, parameters from all subcategories of the main category "General welfare assessment" can be considered relevant to all studies with an interest in assessing animal welfare. The distribution in Fig. 1 is therefore not relevant for comparison between the subcategories of the clinical parameters, but only for comparison between the two main categories and for getting an overview of the representation of parameters for general welfare assessment.

Conclusions about the importance of a certain aspect for assessing animal welfare may be influenced by the relative amount of information about that aspect included in the assessment (Wojciechowska et al., 2005a). Unfortunately, a more detailed recording, e.g. for comparison of the number of parameters used in each (sub-) category could not be done as the level of detail offered in the papers concerning the parameters varies extensively. It is the authors' impression though, that in general the parameters relating to clinical aspects are more numerous and detailed than the parameters relating to a general animal welfare assessment, which - if used at all - are often crude. 


\subsection{Global questions}

Global questions are asked to get an overall assessment e.g. of welfare (Fayers and Machin, 2000). Such questions can relate to the owner's satisfaction with the outcome, decision to treat, the animal's welfare, whether the owners would do it again and would recommend the treatment to others, or owners may be asked to rate the animal's welfare on a scale and perhaps compare the welfare before, during and after treatment. Of the studies reported here 25 (78\%) make use of global questions for the welfare assessment. In 10 studies (31\%) the global question(s) are the only support for the welfare assessment besides the clinical parameters. In 2 studies (6\%) neither global questions nor parameters concerning a general welfare assessment are used.

\subsection{Persons involved}

In most studies (31/97\%) the assessment of animal welfare was based on or supported by owner reports. In many studies, a veterinary assessment (19/59\%) or notes from medical records (5/16\%) were also included. Thus the same study could make use of more than one source of information. The veterinarian(s) involved in the assessment could be the one currently treating the animal, a specialist, the referring vet or a combination of these. No studies made use of an independent person for the assessment, although this possibility was suggested in one of the papers (Mellanby et al., 2003).

\section{Discussion}

The assessment of animal welfare is a complex matter. It involves many scientific disciplines and can be done by a variety of approaches. Already the choice in this paper to mainly use the term "welfare" may raise a question of whether this is the same or different from e.g. "quality of life", "health-related quality of life" or "well-being". None of these terms have been clearly defined, and there is no consensus on what aspects of an assessment may be covered in the context of one rather than the other.

The majority of the papers in this analysis use the term "quality of life". No papers comment on the choice of terminology, but one explanation for this choice could be that when veterinarians carry out follow-up studies they look for inspiration in human medicine where the term "quality of life" is 
the phrase typically used. Indeed, some papers make direct reference to assessment of quality of life in similar human medical conditions (Bateman et al., 1994; Skurla et al., 2000; Oyama et al., 2001; Mellanby et al., 2003). The assessment of human quality of life and animal welfare may certainly have a lot in common. However, due to e.g. the differences in biology and ability to self-report there are also important differences (see McMillan (2000) and Wojciechowska and Hewson (2005) for discussions on assessment by proxy). If the assumption above is correct, i.e. that veterinarians do seek inspiration in human medicine, there may be a lack of awareness within the veterinary community about the ethological approaches to assessment of animal welfare - knowledge that could be beneficial in a veterinary context.

Defining and assessing "welfare" or "(health-related) quality of life" has been the focus of several papers within philosophy (e.g. Griffin, 1986; Sandøe, 1996; Sandøe, 1999; Appleby and Sandøe, 2002), ethology and veterinary medicine (e.g. Webster, 1994; Broom, 1996; Duncan and Fraser, 1997; McMillan, 2000; Scott et al., 2001; Fraser, 2003; Scott et al., 2003; Wojciechowska and Hewson, 2005) and human medicine (e.g. Bowling, 1997; Dijkers, 1999; Fayers and Machin, 2000). It could therefore be expected that references to this work would be made when using these terms in a veterinary contexts. However, only four papers offered some information about what was meant by "quality of life" (Bateman et al., 1994; Lord and Podell, 1999; Brissot et al., 2004; Craven et al., 2004), and none made reference to definitions presented in other papers. The discussions in philosophy and ethology have shown that a concept such as "animal welfare" can have different meanings for different people. This means, that there is not always agreement about what matters for the welfare to be considered good or bad. However, it is very valuable for the reader of followup studies to know what was considered important in the welfare assessment - otherwise the interpretation of the conclusion regarding animal welfare is left open.

In a veterinary context the underlying framework for assessing animal welfare may be different from the typical ethological study as the animal is usually affected by some medical condition or treatment. Naturally, evaluation of the condition or treatment will primarily be based on parameters relating directly to clinical aspects. However, to make a full welfare assessment parameters reflecting all three subcategories of the "General welfare assessment" will be necessary, although obviously the nature, breath, depth and detail of parameters from each subcategory will depend on 
the study in question. With the lack of or use of only crude parameters for a general welfare assessment, there is a potential risk of missing signs of poor welfare.

The use of global questions allows the responder to define e.g. "welfare" in a way that is personally meaningful (Fayers and Machin, 2000), an approach typically used in veterinary medicine (McMillan, 2000). There is, however, disagreement about the whether asking such questions is useful (Fayers and Machin, 2000). Owners' responses to questions about their satisfaction may very well relate to the perceived welfare of the animal, but a number of other aspects may be reflected in the responses as well (Carberry and Harvey, 1987). Using owner satisfaction with the treatment as a measure of animal welfare is thus questionable. Furthermore, if the owner does not consider complications and side effects important (although they are present) these may not affect their responses. The lack of direct association between satisfaction and presence of complications is demonstrated clearly in two studies with high satisfaction rates despite also reporting high rates of complications (Oyama et al., 2001; Mellanby et al., 2003). The majority of follow-up studies in this analysis used global questions to support the welfare assessment (78\%), and in $31 \%$ of the studies this was the only support besides the clinical parameters. One could argue that the potential variation in owner interpretations of global questions could reflect that of the general dog or cat owner population, and as such having an overall percentage of satisfied owners would be a useful guideline. However, for the individual owner facing the decision to perhaps let their animal proceed with a certain treatment it can be important to know the basis for conclusions regarding the animal's welfare, i.e. more specifically to know what to expect. Global questions concerning the welfare of the animal will therefore usually not be sufficient. Giving more specific questions and reporting the answers in the articles makes it possible for the readers to draw their own conclusions.

In almost all studies (97\%) the welfare assessments are made by the owner of the animal sometimes complemented by assessments done by veterinarians or notes from medical records. One potential problem with this approach is that owners and vets may perceive a problem (Bauer et al., 1992) or its impact on animal welfare (Fox et al., 1997) differently, leaving room for different interpretations. Another problem is that notes in medical records may have been made from a different perspective and for a different purpose than that of a follow-up study, and thus these may not provide all the information that could have been relevant for the context of the study. In the 
follow-up studies analysed here veterinarians and owners could assess different aspects of welfare (when both being part of the assessment). Naturally, the veterinarian would typically assess the clinical parameters, but these are often supported by owner reports. Information from owners may provide important additional information, e.g. Mallery et al. (1999) found great variation between information given by owners and from medical records; and the time to recover, as determined by owners, was on average twice as long as the length of veterinary treatment (Rochlitz, 2004). It may thus be necessary to include both to get a fuller picture.

No papers mention whether the questionnaires used for owner assessment have been validated before the follow-up study. Some papers report additional comments made by owners (Bauer et al., 1992; Slater, 1996; Fox et al., 1997; Kirpensteijn et al., 1999; Skurla et al., 2000; Malik et al., 2001; Mellanby et al., 2003). When given this option, owners may volunteer much more detailed information - and sometimes of a different nature - than what seemed to be the intention with the original question. Two papers (which did not meet the inclusion criteria for the analysis here) demonstrate this point very well. Withrow and Hirsch (1979) asked owners about the animal's performance after amputation of a leg. The authors state that all owners replied that after adjustment the animal was as active and happy as before the amputation. The owners' comments to this question as presented by the authors further provide information on aspects concerning "Treatment" (time to recover), "Functionality" (ability to hunt, swim, run, jump), "Social behaviour" (outcome of fights), and "Mental state" (changes in personality). Likewise, Carberry and Harvey (1987) asked about the animal's ability to function well and the owner's satisfaction with the decision to have the animal's limb amputated. It is unclear whether owners' comments are made in response to one or the other question, but the selected comments presented by the authors cover all parameter categories in the analysis presented in this paper. Thus it seems that with no validation or additional communication with owners about their responses, there may be a risk that the owners answer the questions from different perspectives than what was intended from the questions posed by the veterinarians.

Another potential problem relating to owner and veterinary assessment of welfare is that neither the owner nor the veterinarian may have sufficient knowledge to make a full welfare assessment. It has been claimed that making a welfare assessment requires knowledge about the biology and 
behaviour of the species assessed; the methods used by the animals to cope with difficulties; the species-specific responses to illness, pain and distress, and signs that coping is failing, as well as the environmental and social factors that modify these behaviours (Broom and Johnson, 1993; Mench and Mason, 1997; Wojciechowska et al., 2005a). Knowledge is recognised as a factor amongst many that may influence the owner's welfare assessment (Rochlitz, 2004), and while owners have been found to be able to observe behavioural disturbances (Wiseman-Orr et al., 2004), they may be unable to distinguish e.g. degrees of lameness (Priddy et al., 2003), or may even misinterpret their animal's behaviour (Wojciechowska et al., 2005a). Veterinarians can assess the animal's physical health, but often rely on owner reports for assessment of behaviour and mental state. Without the necessary ethological knowledge, the owner may be able to report but not interpret the behaviour correctly - and neither may the veterinarians (Wojciechowska and Hewson, 2005). Specialised knowledge about ethology is only to a limited extent, if at all, part of the veterinary curriculum. Veterinarians are trained to consider the health and physical needs of animals rather than behavioural and mental aspects (Wojciechowska et al., 2005a). While illness can have a negative impact on welfare, the absence of illness does not necessarily mean that welfare is good (Wojciechowska et al., 2005b), and emphasising physical health and ignoring behavioural and mental aspects in the welfare assessment puts the veterinary assessment at risk of being incomplete (Wojciechowska and Hewson, 2005). In relation to promotion of a behaviour wellness concept in veterinary practice, Hetts et al. (2004) point out that training in the basics of animal behaviour is often lacking in the veterinary curriculum and they list as a requirement the education of veterinarians in basic applied ethology. The question therefore is whether veterinarians have the necessary ethological knowledge to make a full welfare assessment, and one could argue that they are educated primarily to recognise signs of failure to cope when these lead to pathological conditions. The "knowledge factor" may therefore play a part also in the questionnaire design and assessment made by the veterinarian. One implication of this potential lack of knowledge is a possibility for both owners and veterinarians to overlook or misinterpret signs of poor welfare.

A final potential problem is that both the owner and the veterinarian may have an interest in a positive outcome of the welfare assessment. For the owner it may be hard to face having put the animal through a treatment which was perhaps expensive and not entirely successful and therefore it may be tempting, maybe subconsciously, to support their choice of treatment by downplaying any 
difficulties observed. The veterinarians involved are often those whose field of expertise is the treatment in question. A negative assessment could have implications for the justification of treatments that perhaps hold a potential for suffering and for the promotion of that particular field of work.

\section{Implications}

The results of this analysis have severe implications for the usefulness of follow-up studies as a basis for advice in the veterinary clinic. The lack of definitions, the choice of parameters and the knowledge and perspectives of those making the assessment leave the reader with a lot of room for interpretation. Adding to this, it is uncertain whether the questionnaires used for owner assessment have been validated before being used in the studies. These aspects raise a problem concerning the validity of the studies - although animal welfare may be considered, the values and scientific basis for the assessment are unclear and leave room for doubts about what is actually assessed. An additional problem is that from an ethological point of view the choice of parameters may be considered inadequate for making a sensitive welfare assessment, i.e. with sufficient breadth, depth and detail. Finally, the assessors' professional and personal involvement and potential desires for a positive outcome may introduce a bias in the assessment, and one could question whether conclusions about animal welfare in follow-up studies are impartial. The value of follow-up studies as a basis for advice for other veterinarians in practice depends on the general applicability of the conclusions - the veterinarian facing a pet owner asking for advice regarding a certain treatment may be faced with other circumstances or understandings of welfare than that of a relevant study. Transparency and validation of welfare assessment instruments are therefore important to enable readers to consider the conclusions of the studies in their proper context.

An important point to consider is how representative the findings in this analysis are of the welfare assessments made in a veterinary context and in particular of assessments made in relation to follow-up studies. The studies included in this analysis show great variation in the approaches to welfare assessment, but the findings concerning the lack of definitions and specific parameters for assessing welfare support the findings of McMillan (2000) in a review of the use of the term "quality of life" in veterinary medicine. The studies analysed in this paper were expected to include 
a welfare assessment because the words "welfare", "quality of life" and "well-being" were mentioned. This assumption may of course be wrong and indeed, the authors do not necessarily mention these terms as part of the follow-up study's purpose. It is possible however, that the assumption is correct, but that the understanding in a veterinary context of what is necessary to include in a welfare assessment is different from the understanding typically seen in an ethological context. Whether such a possible difference could reflect a conscious choice on the veterinarians' part or a lack of awareness about the approaches used in applied ethology is unknown. In a recent newsletter the Federation of Veterinarians of Europe (FVE, 2005) stated that, "only the veterinary profession possesses the knowledge and skills necessary for the assessment of animal welfare, the identification of the causes of poor welfare and the recommendations to correct it". The claim is made in a different context than the focus of this paper, there may be cultural differences between e.g. Europe and the U.S.A., and many veterinarians may disagree (including the one co-authoring this paper), still, as a statement from a European veterinary organisation, it reflects a quite disturbing disregard for the knowledge and experience held in the field of applied ethology.

\section{Instruments for animal welfare assessment}

In human medicine a number of instruments have been developed for general assessments (generic instruments) as well as for use in relation to specific medical conditions (Fayers and Machin, 2000). In recent years a few instruments for assessment of animal welfare in a veterinary context have also been developed for general welfare assessment (Hartmann and Kuffer, 1997; McMillan, 2003; Wojciechowska et al., 2005a; Wojciechowska et al., 2005b) and disease-specific welfare assessment (Wiseman-Orr et al., 2004 (chronic pain); Freeman et al., 2005 (cardiac disease); Yazbek and Fantoni, 2005 (pain secondary to cancer)). Some of the instruments have been through a validation processes. (It is beyond the scope of this paper to evaluate the quality of these instruments, but see Wojciechowska and Hewson (2005) for discussion on validation of some of the instruments). Compared to the follow-up studies analysed in this paper, these instruments and the pain instruments mentioned earlier (Holton et al., 2001; Hielm-Björkman et al., 2003; Hudson et al., 2004) are generally more recent and present more nuances regarding animal welfare assessments, i.e. most of them use multiple parameters from the "Functionality", "Social behaviour" and "Mental state" categories. Still, there is a need for more sensitive (Mellanby et al., 2003) and systematic 
(Wojciechowska et al., 2005a) instruments to assess welfare in a veterinary context. Apparently the development of animal welfare assessment instruments for use in veterinary medicine is only in its infancy and the sources listed above are probably just the first of many to come.

\section{A call for ethologists}

Only a few veterinary follow-up studies consider animal welfare at all. Furthermore, there are no standardised ways to assess welfare in these studies. Developing validated standardised instruments could be beneficial for a standardised evaluation of diseases and treatments (Bateman et al., 1994; Yazbek and Fantoni, 2005), they would allow comparison between studies on similar medical conditions, and they could help veterinarians and pet owners in decision-making processes (Wojciechowska and Hewson, 2005). As part of this, research is needed on the influences of individual factors (Wojciechowska and Hewson, 2005; Yazbek and Fantoni, 2005), and particularities of specific diseases (Yazbek and Fantoni, 2005).

Here veterinary medicine can clearly benefit from the expertise and experiences held in the field of applied ethology. Ethologists can offer thorough knowledge about animal behaviour and experience with instruments for detailed animal behaviour and welfare assessment. Veterinarians specialised in the medical condition evaluated typically carry out the follow-up studies. Although ethology is taught at some veterinary universities and some veterinarians have studied ethology at a later stage, it is doubtful whether veterinarians, alongside their medical expertise, will have the same level of expertise and detailed knowledge about animal behaviour and welfare as an ethologist. An obvious way forward would therefore be to involve ethologists in welfare assessments in a veterinary context. In addition, the ethologist would typically have a more impartial position than the veterinarian and the animal owner. This could help reducing a potential bias in design. Also, assessments may benefit from more independent observers (Mellanby et al., 2003).

\section{Potential contributions from ethology}

Ethology can contribute to developing the quality of welfare assessments in follow-up studies in several ways. First, contributions could be made concerning the implications of welfare definitions for welfare assessments, which could help clarify what was considered important for animal 
welfare. Secondly, parameters and assessment tools for more sensitive animal welfare assessments could be developed and validated. Such instruments could be useful both when evaluating a particular treatment in a scientific context and when evaluating the situation for an individual animal in either prospective or retrospective follow-up studies. They might also be a helpful support for the practising veterinarian doing welfare assessments on a daily basis in the clinic.

Typically a wide range of behaviours and signals are studied in ethological welfare assessments (see e.g. Mills et al., 2003; Schilder and van den Borg, 2004). Using a wide range of behaviours makes it possible to assess more nuances of the state of the animal. The respective behaviours and signals have to have been validated in other more controlled situations. This approach contrasts with the one seen in most of the analysed follow-up studies where only very restricted ranges of behaviours, if any, are used. Investigations that have studied the different approaches to assessments show that a more comprehensive view will come to other conclusions than those reached using a more simple scale, even when the investigation has focused on a small part of welfare relevant behaviours, such as those related to pain (Hardie et al., 1997; Hielm-Björkman et al., 2003). If the focus of assessment is more all encompassing, e.g. "welfare", it seems likely that the need for a variety of variables is even more pronounced. There are at least four main areas in which ethology might be of a special interest in a veterinary welfare assessment.

The first area is the use of spontaneously occurring behaviour to assess the subjective experiences of the animal. In ethology there is a strong tendency, and indeed recommendation, to use nonsubjective labels on animal behaviour (see e.g. Martin and Bateson's (1998) book on behavioural observations, p. 58). In the subsequent analysis of the behaviours they are, however, often interpreted in a more subjective way using words such as fear and frustration, words that denote subjective states. The approach used that goes the furthest in this direction is the one developed by Wemelsfelder and colleagues (e.g. Wemelsfelder et al., 2001) in which such words are used as direct interpretations of the state of the animal, bypassing quantitative measures; a methodology that may offer new approaches for animal welfare assessments in a veterinary context.

The second area deals with the use of behavioural tests, both functional and those used to assess the motivational or emotional state of the animal. Many of the tests are perhaps less appropriate when evaluating the treatment of the individual animal (since they often require special material or extra 
personnel), but they might be relevant tools for evaluating the effect of a given treatment in a research situation. Among the tests used to assess a range of response tendencies is the Swedish Dog Mentality test which has received some recent attention, both when it comes to external validation and repeatability etc. (Svartberg, 2005; Svartberg et al., 2005). Other attempts at estimating the emotional predispositions of dogs include a questionnaire by Serpell and Hsu (2001), and an experimental approach founded in human emotional theory (Sheppard and Mills, 2002). As mentioned above the behavioural tests might in many cases be relevant for research e.g. evaluating the welfare consequences of a given treatment. In some cases simple behavioural tests might also be used, either by the owner or the veterinarian to evaluate the situation for an individual animal. There are however very few of these tests available and there is a real need for ethologists to help with the design of such tests for companion animals. For example, with reference to a system used in human patients Skurla et al. (2000) suggested the use of a survey prior to hip surgery in dogs and at various set times after, allowing the animal's condition before and after to be compared and possible deterioration over time to be identified. Kirpensteijn et al. (1999) mentioned that behaviour can change in dogs following limb amputation and suggested that a change in functional status may result in a lower position in the rank order when interacting with other dogs. They could not, however, determine the reason for the changes observed, and it is likely that ethologists would be able to contribute to further research on this matter. Indeed, Rochlitz (2004) pointed out that an objective way of assessing recovery following such amputations could be useful.

The third area of research in applied ethology that might prove useful is the integration of physiological measures in the two previous approaches to help assess and understand the state of the animal. There is extensive literature on this in farm animals but the area needs to be further developed for companion animals. Jankowski et al. (1998) considered the possibility of identifying hormonal and physiological changes caused by pain, due to cats' apparently subtle outwards signs of pain. But they found the clinical usefulness of the methods involved limited. The non-invasive methods that have been developed e.g. regarding salivary cortisol or heart rate may be of special interest in this context (see e.g. Väisänen et al., 2005).

The final research area concerns the basic knowledge regarding the behaviour and welfare of companion animals. Although some is known about welfare assessment in dogs and cats, there is a need for further basic research on behaviour and welfare to identify the factors most relevant to a 
welfare assessment (Wojciechowska et al., 2005a). The literature search on follow-up studies revealed only studies concerning dogs and cats. No studies on other companion animals, e.g. guinea pigs, hamsters, rabbits, birds and reptiles were identified. An obvious reason for this is probably that complicated veterinary procedures are not carried out in these species and thus there has not been a perceived need to conduct follow-up studies. At this point only limited information is available on welfare assessment in rodents, birds and reptiles (with the exception of studies in relation to laboratory animals, for an overview see e.g. Hawkins et al., 2004). However, considering the increasing interest in keeping more exotic pets, and the advances in veterinary medicine it is likely that in the future there will be a need to address welfare concerns in relation to veterinary treatment in many different animals.

\section{Conclusions}

A search of the literature showed only a few follow-up studies in veterinary medicine that went beyond an evaluation of the medical condition and treatment, and considered animal welfare. The analysis of the follow-up studies that did explicitly consider animal welfare showed that due to a lack of definitions, a lack of sensitivity in the assessment and a potential bias, the general applicability of conclusions regarding animal welfare from follow-up studies could be limited. One implication of this is that these studies may have limited use as a basis for advice in the veterinary clinic.

Considering the increasingly advanced treatments offered in small animal practice, the need to evaluate not only the treatment itself but also the implications of the treatment for the general welfare of the animal can be expected to grow. In future work attention should be paid to definitions, a broader and more detailed animal welfare assessment, and a reduction of potential bias. The development of validated instruments could be beneficial and has begun, and the field of ethology and ethologists can make valuable contributions to this development. Improving the quality of welfare assessment in a veterinary context can be a new challenge for applied ethologists and can be of benefit to veterinary medicine, animals and their owners. 


\section{Acknowledgements}

The authors wish to thank Peter Sandøe for valuable comments on an earlier version of the manuscript.

\section{References}

Appleby, M. C., Sandøe, P., 2002. Philosophical debate on the nature of well-being: implications for animal welfare. Anim. Welfare 11, 283-294.

Bass, M., Howard, J., Gerber, B., Messmer, M., 2005. Retrospective study of indications for and outcome of perineal urethrostomy in cats. J. Small Anim. Pract. 46, 227-231.

Bateman, K.E., Catton, P.A., Pennock, P.W, Kruth, S.A., 1994. 0-7-21 Radiation therapy for the palliation of advanced cancer in dogs. J. Vet. Intern. Med. 8, 394-399.

Bauer, M., Glickman, N., Glickman, L., Toombs, J., Golden, S., Skowronek, C., 1992. Follow-up study of owner attitudes toward home care of paraplegic dogs. J. Am. Vet. Med. Assoc. 200, 18091816.

Boothe, H.W., Howe, L.M., Edwards, J.F., Slater, M.R., 1996. Multiple extrahepatic portosystemic shunts in dogs: 30 cases (1981-1993). J. Am. Vet. Med. Assoc. 208, 1849-1854.

Bowling, A., 1997. Measuring health: a review of quality of life measurement scales. $2^{\text {nd }}$ ed. Open University Press, Buckingham.

Brissot, H.N., Dupré, G.P., Bouvy, B.M., 2004. Use of laparatomy in a staged approach for resolution of bilateral or complicated perineal hernia in 41 dogs. Vet. Surg. 33, 412-421.

Broom, D.M., 1996. Animal welfare defined in terms of attempts to cope with the environment. Acta agri. scand., suppl. 27, 22-28.

Broom, D.M., Johnson, K.G., 1993. Stress and animal welfare. Chapman \& Hall, London, UK.

Brønden, L.B., Rutteman, G.R., Flagstad, A., Teske, E., 2003. Study of dog and cat owners' perceptions of medical treatment for cancer. Vet. Rec. 152, 77-80.

Carberry, C.A., Harvey, H.J., 1987. Owner satisfaction with limb amputation on dogs and cats. J. Am. Anim. Hosp. Assoc. 23, 227-232.

Craven, M., Simpson, J.W., Ridyard, A.E., Chandler, M.L., 2004. Canine inflammatory bowel disease: retrospective analysis of diagnosis and outcome in 80 cases (1995-2002). J. Small Anim. Pract. 45, 336-342.

Dawkins, M., 1980. Animal suffering. Chapman and Hall. London, UK. 
Dijkers, M., 1999. Measuring quality of life: methodological issues. Am. J. Phys. Med. Rehabil. 78, 286-300.

Duncan, I.H.J., Fraser, D., 1997. Understanding animal welfare. In: Appleby, M.C., Hughes, B.O. (Eds.), Animal Welfare. CAB International, pp. 19-31.

Fayers, P.M., Machin, D., 2000. Quality of life: assessment, analysis and interpretation. John Wiley \& Sons Ltd, UK.

Fox, L.E., Geoghegan, S.L., Davis, L.H., Hartzel, J.S., Kubilis, P., Gruber, L.A., 1997. Owner satisfaction with partial mandibulectomy or maxillectomy for treatment of oral tumors in 27 dogs. J. Am. Anim. Hosp. Assoc. 33, 25-31.

Fox, L.E., Rosenthal, R.C., King, R.R., Levine, P.B., Vail, D.M., Helfand, S.C., MacEwen, E.G., Perez-Soler, R., Calderwood-Mays, M., Kurzman, I.D., 2000. Use of cis-bis-neodecanoato-transR,R-1, 2-diaminocyclohexane platinum (II), a liposomal cisplatin analogue, in cats with oral squamous cell carcinoma. Am. J. Vet. Res. 61, 791-795.

Fraser, D., 2003. Assessing animal welfare at the farm and group level: The interplay of science and values. Anim. Welfare 12, 433-443.

Freeman, L.M., Rush, J.E., Farabaugh, A.E., Must, A., 2005. Development and evaluation of a questionnaire for assessing health-related quality of life in dogs with cardiac disease. J. Am. Vet. Med. Assoc. 226, 1864-1868.

FVE, 2005. Federation of Veterinarians of Europe, Newsletter - September 2005, p.6.

Griffin, J., 1986. Well-Being, Its meaning, measurement and moral importance. Clarendon Paperbacks, Oxford.

Hardie, E.M., Hansen, B.D., Carroll, G.S., 1997. Behaviour after ovariohysterectomy in the dog: what's normal? Appl. Anim. Behav. Sci. 51, 111-128.

Hartmann, K., Kuffer, M., 1997. Modifikation des Karnofsky-Indexes für die Katze zur Beurteilung der Lebensqualität und zur Therapiekontrolle. Tierärtztl. Prax. 25, 540-542.

Hawkins, P., Grant, G., Raymond, R., Hughes, G., Morton, D., Mason, G., Playle, L., Hubrecht, R., Jennings, M., 2004. Reducing suffering through refinement of procedures: report of the 2003 RSPCA/UFAW rodent welfare group meeting. Anim. Technol. Welf. 3, 79-85.

Hetts, S., Heinke, M.L., Estep, D.Q., 2004. Behaviour wellness concepts for general veterinary practice. J. Am. Vet. Med. Assoc. 225, 506-513.

Hielm-Björkman, A.K., Kuusela, E., Liman, A., Markkola, A., Saarto, E., Huttunen, P., Leppäluoto, J., Tulamo, R-M., Raekallio, M., 2003. Evaluation of methods for assessment of pain associated with chronic osteoarthritis in dogs. J. Am. Vet. Med. Assoc. 222, 1552-1558. 
Holt, P.E., Durdey, P., 1999. Transanal endoscopic treatment of benign canine rectal tumours: preliminary results in six cases (1992-1996). J. Small Anim. Pract. 40, 423-427.

Holton, L., Reid, J., Scott, E.M., Pawson, P., Nolan, A., 2001. Development of a behaviour-based scale to measure acute pain in dogs. Vet. Rec. 148, 525-531.

Hudson, J.T., Slater, M.R., Taylor, L., Scott, H.M., Kerwin, S.C., 2004. Assessing repeatability and validity of a visual analogue scale questionnaire for use in assessing pain and lameness in dogs. Am. J. Vet. Res. 65, 1634-1643.

Jankowski, A.J., Brown, D.C., Duval, J., Gregor, T.P., Strine, L.E., Ksiazek, L.M., Haines, A., 1998. Comparison of effects of elective tenectomy or onychectomy in cats. J. Am. Vet. Med. Assoc. 213, 370-373.

Jeffery, N., Brearley, M.J., 1993. Brain tumours in the dog: Treatment of 10 cases and review of recent literature. J. Small Anim. Pract. 34, 367-372.

Johnson, C.A., Armstrong, P.J., Hauptman, J.G., 1987. Congenital portosystemic shuts in dogs: 46 cases (1979-1986). J. Am. Vet. Med. Assoc. 191, 1478-1483.

Kirpensteijn, J., Van den Bos, R., Endenburg, N., 1999. Adaptation of dogs to the amputation of a limb and their owners' satisfaction with the procedure. Vet. Rec. 144, 115-118.

Lord, L.K., Podell, M., 1999. Owner perception of the care of long-term phenobarbital-treated epileptic dogs. J. Small Anim. Pract. 40, 11-15.

Macintire, D.K., Vincent-Johnson, N.A., Kane, C.W., Lindsay, D.S., Blagburn, B.L., Dillon, A.R., 2001. Treatment of dogs infected with Hepatozoon americanum: 53 cases (1989-1998). J. Am. Vet. Med. Assoc. 218, 77-82.

Martin, P., Bateson, P., 1998. Measuring behaviour. An introductory guide. Cambridge: Cambridge University Press.

Malik, R., Gabor, L.J., Foster, S.F., McCorkell, B.E., Canfield, P.J., 2001. Therapy for Australian cats with lymphosarcoma. Austr. Vet. J. 79, 808-817.

Mallery, K.F., Freeman, L.M., Harpster, N.K., Rush, J.E., 1999. Factors contributing to the decision for euthanasia of dogs with congestive heart failure. J. Am. Vet. Med. Assoc. 214, 2101-1204.

McCaw, D.L., Miller, M.A., Bergman, P.J., Withrow, S.J., Moore, A.S., Knapp, D.W., Fowler, D., Johnson, J.C., 1997. Vincristine therapy for mast cell tumors in dogs. J. Vet. Intern. Med. 11, 375378.

McMillan, F.D., 2000. Quality of life in animals. J. Am. Vet. Med. Assoc. 216, 1904-1910.

McMillan, F.D., 2003. Maximizing quality of life in ill animals. J. Am. Anim. Hosp. Assoc. 39, 227-235. 
Mellanby, R.J., Herrtage, M.E., Dobson, J.M., 2003. Owner's assessment of their dog's quality of life during palliative chemotherapy for lymphoma. J. Small Anim. Pract. 44, 100-103.

Mench, J.A., Mason, G.J., 1997. Behaviour. In: Appleby, M.C., Hughes, B.O. (Eds.), Animal Welfare. CAB International, pp. 127-141.

Meyer, H.P., Rothuizen, J., van Sluijs, F.J., Voorhout, G., van den Brom, W.E., 1999. Progressive remission of portosystemic shunting in $23 \mathrm{dogs}$ after partial closure of congenital portosystemic shunts. Vet. Rec. 144, 333-337.

Mills D.S., Estelles M.G., Coleshaw P.H., Shorthouse C., 2003. Retrospective analysis of the treatment of firework fears in dogs. Vet. Rec. 153, 561-562.

Oglivie, G.K., Moore, A.S., Obradovich, J.E., Elmslie, R.E., Vail, D.M., Straw, R.C., Salmon, M.D., Klein, M.K., Atwater, S.W., Ciekot, P.E., LaRue, S.M., Peaston, A., Withrow, S.J., 1993. Toxicosis and efficacy associated with administration of mitoxantrone to cats with malignant tumors. J. Am. Vet. Med. Assoc. 202, 1839-1844.

Oyama, M.A., Sisson, D.D., Lehmkuhl, L.B., 2001. Practices and outcome of artificial cardiac pacing in 154 dogs. J. Vet. Intern. Med. 15, 229-239.

Priddy II, N.H., Tomlinson, J.L., Dodam, J.R., Hornbostel, J.E., 2003. Complications with and owner assessment of the outcome of tibial plateau leveling osteotomy for treatment of cranial cruciate ligament rupture in dogs: 193 cases (1997-2001). J. Am. Vet. Med. Assoc. 222, 1726-1732.

Ranen, E., Shamir, M.H., Shahar, R., Johnston, D.E., 2004. Partial eosophagectomy with single layer closure for treatment of oesophageal sarcomas in 6 dogs. Vet. Surg. 33, 428-434.

Rochlitz, I., 2004. The effects of road traffic accidents on domestic cats and their owners. Anim. Welfare 13, 51-55.

Sandøe, P., 1996. Animal and human welfare - are they the same kind of thing?. Acta agri. scand., suppl. 27, 11-15.

Sandøe, P., 1999. Quality of life - three competing views. Ethical Theory Moral Pract. 2, 11-23.

Scott, E.M., Nolan, A.M., Fitzpatrick, J.L., 2001. Conceptual and methodological issues related to welfare assessment: a framework for measurement. Acta Agrc. Scan., Sect. A., Animal Sci., suppl. 30, 5-10.

Scott, E.M., Fitzpatrick, J.L., Nolan, A.M., Reid, J., Wiseman, M.L., 2003. Evaluation of a welfare state based on interpretation of multiple indices. Anim. Welfare 12, 457-468.

Schilder, M.B.H., van den Borg, J.A.M., 2004. Training dogs with the help of the shock collar: short and long term behavioural effects. Appl. Anim. Behav. Sci. 85, 319-334. 
Serpell, A.J., Hsu, Y., 2001. Development and validation of a novel method for evaluating behavior and temperament in guide dogs. Appl. Anim. Behav. Sci. 72, 347-364.

Sheppard, G., Mills, D.S., 2002. The development of a psychometric scale for the evaluation of the emotional predispositions of pet dogs. Int. J. Comp. Psychol. 15, 201-222.

Skurla, C.T., Egger, E.L., Schwarz, P.D., James, S.P., 2000. Owner assessment of the outcome of total hip arthroplasty in dogs. J. Am. Vet. Med. Assoc. 217, 1010-1012.

Slater, M.R., Barton, C.L., Rogers, K.S., Peterson, J.L., Harris, C.K., Wallace, K., 1996. Factors affecting treatment decision and satisfaction of owners of cats with cancer. J. Am. Vet. Med. Assoc. 208, 1248-1252.

Smith, K.R., Bauer, M., Monnet, E., 1995. Portosystemic communications: Follow-up of 32 cases. J. Small Anim. Pract. 36, 435-440.

Snelling, S.R., Edwards, G.A., 2003. A retrospective study of unilateral arytenoid lateralisation in the treatment of laryngeal paralysis in 100 dogs (1992-2000). Aust. Vet. J. 81, 464-468.

Stone, E.A., Withrow, S.J., Page, R.L., Schwarz, P.D., Wheeler, S.L., Seim III, H.B., 1988. Ureterocolonic anastomosis in ten dogs with transitional cell carcinoma. Vet. Surg. 17, 147-153.

Svartberg, K., 2005. A comparison of behaviour in test and in everyday life: evidence of three consistent boldness-related personality traits in dogs. Appl. Anim. Behav. Sci. 91, 103-128.

Svartberg, K., Tapper, I., Temrin, H., Radesäter, T., Thorman, S., 2005. Consistency of personality traits in dogs. Anim. Behav. 69, 283-291.

Väisänen, M., Valros, A.E., Hakaoja, E., Raekallio, M.R., Vainio, O.M, 2005. Pre-operative stress in dogs - a preliminary investigation of behavior and heart rate variability in healthy hospitalized dogs. Vet. Anaesth. Analg. 32, 158-167.

Watson, P.J., Herrtage, M.E., 1998. Medical management of congenital portosystemic shunts in 27 dogs - a retrospective study. J. Small Anim. Pract. 39, 62-68.

Webster J., 1994. Animal Welfare. A cool eye towards Eden. Blackwell Science Ltd., UK.

Wemelsfelder, F., Hunter, T.E.A., Mendl, M.T., Lawrence, A.B., 2001. Assessing the "whole animal": a free choice profiling approach. Anim. Behav. 62, 209-220.

Wiseman-Orr, M.L., Nolan, A.M., Scott, E.M., 2004. Development of a questionnaire to measure the effects of chronic pain on health-related quality of life in dogs. Am. J. Vet. Res. 65, 1077-1084.

Withrow, S.J., 1980. Application of cryosurgery to primary malignant bone tumors in dogs (Phase 1 study). J. Am. Anim. Hosp. Assoc. 16, 493-495.

Withrow, S.J., Hirsch, V.M., 1979. Owner response to amputation of a pet's leg. Vet. Med. Small Anim. Clin. 74, 332-334. 
Wojciechowska, J.I., Hewson, C.J., 2005. Quality-of-life assessment in pet dogs. J. Am. Vet. Med. Assoc. 226, 722-728.

Wojciechowska, J.I., Hewson, C.J., Stryhn, H., Guy, N.C., Patronek, G.J., Timmons, V., 2005a. Development of a discriminative questionnaire to assess nonphysical aspects of quality of life of dogs. Am. J. Vet. Res. 66, 1453-1460.

Wojciechowska, J.I., Hewson, C.J., Stryhn, H., Guy, N.C., Patronek, G.J., Timmons, V., 2005 b. Evaluation of a questionnaire regarding nonphysical aspects of quality of life in sick and healthy dogs. Am. J. Vet. Res. 66, 1461-1467.

Yazbek, K.V.B., Fantoni, D.T., 2005. Validity of a health-related quality-of-life scale for dogs with signs of pain secondary to cancer. J. Am. Vet. Med. Assoc. 226, 1354-1358.

Yearley, J.H., Hancock, D.D., Mealey, K.L., 2004. Survival time, lifespan and quality of life in dogs with idiopathic Fanconi syndrome. J. Am. Vet. Med. Assoc. 225, 377-383. 